\title{
AVALIAÇÃO DA DEPOSIÇÃO DE CALDA EM ANTERAS DE TRIGO, PARA O ESTUDO DO CONTROLE QUÍMICO DE GIBERELA (Gibberella zeae) ${ }^{1}$
}

\author{
EDIVAN PANISSON ${ }^{2}$, WALTER BOLLER ${ }^{3}$, ERLEI M. REIS ${ }^{4}$
}

RESUMO: A giberela, causada pelo fungo Gibberella zeae (Fusarium graminearum), é uma importante doença de infecção floral do trigo. Para controlar essa doença, o fungicida deve ser aplicado durante a antese, de modo a proteger as anteras. Os objetivos do presente trabalho foram de construir uma barra de pulverização que permitiu utilizar bicos em diferentes arranjos e quantificar a presença de corante nas anteras quando aplicado com diferentes pontas de pulverização, direções dos bicos na barra e com diferentes volumes de calda. Utilizaram-se pontas de jato plano (XR-11002), jato plano duplo (110DB2) e jato cônico vazio (JA-2), espaçadas em 0,50 m, em uma barra tradicional e numa barra modificada. Na barra modificada, foram utilizados corpos duplos giratórios, posicionandose os bicos na vertical, $30^{\circ}$ ou $45^{\circ}$ para frente e para trás em relação à vertical. Os resultados mostraram que a utilização de dois bicos no mesmo ponto da barra aumentou significativamente o número de anteras que receberam o fungicida. As três pontas de pulverização comportaram-se de maneira semelhante. Dois bicos formando ângulo de $30^{\circ}$ em relação à vertical proporcionaram a mesma quantidade de anteras cobertas com corante do que dois bicos posicionados na vertical. A angulação dos bicos em $45^{\circ}$ com a vertical proporcionou maior número de anteras atingidas pela calda.

PALAVRAS-CHAVE: barras de pulverização, pontas de pulverização, anteras soltas e presas.

\section{SPRAY DEPOSITION EVALUATION ON WHEAT ANTHERS TO STUDY THE HEAD BLIGHT (Gibberella zeae) CHEMICAL CONTROL}

SUMMARY: The head blight caused by the fungus Gibberella zeae (Fusarium graminearum) is a major floral disease of wheat. The chemical control is efficient only if the fungicides are applied at the full anthesis to protect anthers. In this research, the main objective was to built such a spray boom to allow different spray nozzles arrangements. The anther staining provided by color dyes applied with different spray nozzles, nozzle arrangements, and spray volumes was also assessed. Two spray booms were used, one with individual nozzles spaced at $0.50 \mathrm{~m}$ and another one mounted with adjustable sets, also spaced at $0.50 \mathrm{~m}$, each one having one nozzle forward $\left(30^{\circ}\right.$ or $\left.45^{\circ}\right)$ and the other backward at an angle of $30^{\circ}$ or $45^{\circ}$. The nozzle types used were flat fan, twin flat fan, and hollow cone. A total of four experiments were carried out. The deposition of color dye was higher on loose than on trapped anthers. The double nozzle sets resulted in increased spray volumes (200 to $400 \mathrm{~L} \mathrm{ha}^{-1}$ ) and higher numbers of fungicide sprayed anthers. The nozzle types did not differ from each other. The anther staining was improved by nozzles positioned at $45^{\circ}$ (forward and backward) but not at $30^{\circ}$.

KEYWORDS: spray booms, loose anthers, trapped anthers.

\footnotetext{
${ }^{1}$ Parte da dissertação de mestrado do primeiro autor, apresentada ao Programa de Pós-Graduação em Agronomia, Faculdade de Agronomia e Medicina Veterinária da Universidade de Passo Fundo - FAMV/UPF. Trabalho parcialmente financiado pela Empresa Bayer Crop Science e apresentado no XXX Conbea.

${ }^{2}$ Eng $^{\circ}$ Agr $^{\circ}$, Mestre em Agronomia, e-mail: mnep@terra.com.br

${ }^{3}$ Eng $^{\circ}$ Agr , Doutor, Docente da FAMV/UPF, Caixa Postal 611, 99001.970, Passo Fundo - RS, Fone/Fax: (0XX54) 316.8151, email: boller@upf.br

${ }^{4}$ Eng $^{\circ}$ Agr $^{\circ}, \mathrm{PhD}$, docente da FAMV/UPF, Passo Fundo - RS.

Recebido pelo Conselho Editorial em: 15-10-2001
}

Aprovado pelo Conselho Editorial em: 12-8-2003

Eng. Agríc., Jaboticabal, v.24, n.1, p.111-120, jan./abr. 2004 


\section{INTRODUÇÃO}

Dentre as doenças do trigo, a giberela é a que apresenta as maiores dificuldades de controle. Essas estão relacionadas com: a) a maioria dos cereais é suscetível ao patógeno; b) nos restos culturais das espécies suscetíveis, são produzidas grandes quantidades de inóculo; c) até o momento, a resistência das cultivares é moderada; d) a esporadicidade da ocorrência dificulta a recomendação de controle químico (REIS, 1988; PARRY et al., 1995; REIS et al., 1996; REIS et al., 1997); e) os fungicidas devem ser aplicados durante a antese, e f) os equipamentos utilizados não propiciam cobertura adequada dos sítios de infecção (REIS et al., 1996).

$\mathrm{Na}$ utilização de fungicidas, deve-se realizar a aplicação no momento correto, de modo a atingir o alvo, depositando a quantidade de ingrediente ativo necessário para o controle do fungo, apresentando segurança ao agroecossistema (VELLOSO et al., 1984; MATUO, 1990; MATTHEWS, 1992; MAROCHI, 1996; OZEKI \& KUNZ, 1998). O momento adequado da aplicação de fungicidas para o controle da giberela é quando for possível ocorrer a máxima exposição das anteras (REIS, 1988; MAULER-MACHNIK \& ZAHN, 1994; REIS et al., 1996). REIS (1988) e VARGAS et al. (2000) estudaram o curso da antese do trigo e verificaram que a máxima quantidade de anteras expostas ocorre do sexto ao oitavo dia após o aparecimento das primeiras anteras.

$\mathrm{O}$ volume de calda pode ter efeito sobre a eficiência dos fungicidas e deve ser utilizado de acordo com o tipo de aplicação a ser executada. TEIXEIRA et al. (1998), estudando o efeito do volume de aplicação com uma ponta de jato plano, observaram aumento significativo da cobertura de alvos planos quando o volume de aplicação passou de 100 para $200 \mathrm{~L} \mathrm{ha}^{-1}$ e não diferindo desse quando utilizaram $300 \mathrm{~L} \mathrm{ha}^{-1}$. Por sua vez, SAYLER (1999), avaliando os efeitos do volume de pulverização com vistas ao controle de giberela, observou que volumes de calda acima de $506 \mathrm{~L} \mathrm{ha}^{-1}$ aumentaram a cobertura das espigas, e acima de $336 \mathrm{~L} \mathrm{ha}^{-1}$ diminuíram a intensidade da doença.

VELLOSO et al. (1984) relatam que pontas de jato cônico, por produzirem gotas menores, são as mais indicadas para pulverizações de fungicidas, porém essas geram gotas mais suscetíveis à deriva do que aquelas geradas pelas pontas de jato plano. Para a aplicação de fungicidas com pulverizadores de barras, SPRAYING SYSTEMS CO. (1999) recomenda a utilização de pontas de jato plano, indicando a utilização de pontas de jato cônico somente para a pulverização em faixas (jato dirigido).

Mc MULLEN (1998) relata que a aplicação de fungicidas com diferentes pontas de pulverização pode proporcionar diferentes níveis de controle de doenças, mas geralmente não são observadas diferenças estatísticas. Descreve ainda que o bico tradicional (ponta de jato plano 8002, mantida na posição vertical) não fornece boa cobertura das espigas para o controle da giberela. A mesma ponta, utilizada segundo um arranjo diferente do tradicional, mantendo dois bicos a cada $0,50 \mathrm{~m}$ da barra, sendo um direcionado para frente e outro para trás, melhorou a cobertura das espigas.

De acordo com MATTHEWS (1992), as gotas finas (diâmetro de 101 a $200 \mu \mathrm{m}$ ) são recomendadas para obter melhor cobertura, e gotas mais grossas $(>300 \mu \mathrm{m})$ para evitar a deriva. CHRISTOFOLETTI (1999) recomenda as categorias de pulverização média (201 a $300 \mu \mathrm{m})$ e fina (91 a $200 \mu \mathrm{m})$ para aplicação de fungicidas.

OZEKI \& KUNZ (1998) recomendam uma densidade de 30 a 50 gotas $\mathrm{cm}^{-2}$ para fungicidas sistêmicos e acima de 70 gotas $\mathrm{cm}^{-2}$ para fungicidas protetores. Para o controle da giberela, mesmo utilizando fungicidas com modo de ação sistêmico, REIS et al. (1988) relatam que esses devem ser considerados como protetores, pois as anteras não apresentam xilema e não translocam essas substâncias.

Tendo em vista que os sítios de infecção da giberela são as anteras, que são difíceis de serem atingidas pelos fungicidas, é oportuna a busca de alternativas para melhorar a deposição da calda nesse alvo biológico. A melhoria das técnicas de aplicação deverá proporcionar melhor cobertura das anteras, trazendo melhores resultados na utilização de fungicidas. 
Os objetivos deste trabalho foram desenvolver uma barra portátil que permita alterar a direção dos bicos e dos seus jatos de pulverização e determinar a cobertura de anteras de trigo com solução corante aplicada por meio de diferentes pontas de pulverização e diferente direcionamento dos jatos em relação à vertical, com a utilização de dois volumes de calda.

\section{MATERIAL E MÉTODOS}

Projetou-se e construiu-se uma barra portátil (Figura 1) que possibilita a utilização de dois bicos em um mesmo ponto, com possibilidade de variar a direção de seus jatos, em relação à vertical (para frente ou para trás), buscando direcionar as gotas para as espigas das plantas de trigo. Na montagem da barra modificada, utilizaram-se corpos de bicos giratórios duplos (QJ8600-2-1/4 NYB), fornecidos pela Spraying Systems Co. (detalhe b2 - Figura 1), que permitiram que os bicos fossem utilizados com diferentes ângulos em relação à vertical. Na barra modificada, os bicos podem ser utilizados em ângulos de até $45^{\circ}$ em relação à vertical (Figura 1 - c).

Para avaliar o desempenho de diferentes tipos de pontas de pulverização, montadas na barra tradicional e na barra modificada, conduziram-se dois experimentos durante a safra de 1999 e dois na safra do ano 2000 (Tabela 1).

Aplicou-se uma solução de corante (Vermelho Sun 11B, líquido - produzido por Orema Indústria e Comércio Ltda.) na concentração de 5\%, para posterior avaliação da quantidade de anteras de trigo atingidas pela calda. A aplicação foi realizada no estádio 65 da escala fenológica de ZADOCKS et al. (1974), com o auxílio de um pulverizador costal pressurizado com $\mathrm{CO}_{2}$. Na barra tradicional, foram montados três bicos espaçados em $0,50 \mathrm{~m}$. Na barra modificada, foram montados seis bicos, utilizando-se de dois bicos a cada $0,50 \mathrm{~m}$ de distância (Figura 1). A configuração das barras possibilitou realizar as pulverizações mediante deslocamento do operador ao lado das parcelas experimentais. Essa forma de condução da barra diminui o risco de contaminação do operador e evita vibrações das plantas tratadas, que poderiam causar o escorrimento da calda recém-depositada no alvo, caso o operador se deslocasse próximo ao centro da parcela. A velocidade de deslocamento foi de 1 $\mathrm{m} \mathrm{s}^{-1}$. As barras foram conduzidas a 0,40 m acima do ápice das espigas. As parcelas, com sete linhas de trigo (cultivar BR 23 em 1999 e Rubi no ano 2000), espaçadas em 0,17 m, mediam 5 m de comprimento.

A amostragem das espigas foi realizada na linha central de cada parcela, a partir de 20 minutos após as aplicações. O material coletado foi acondicionado em sacos de papel identificados, levado ao laboratório e avaliado no dia seguinte.

Em 1999, foi realizada a avaliação em cinco espigas, coletadas ao acaso, na linha central de cada parcela, sendo utilizadas quatro repetições de cada tratamento. Em 2000, foi realizada a avaliação em cinco espigas coletadas da mesma forma que em 1999, utilizando-se de três repetições por tratamento. Determinou-se a deposição do corante nas anteras soltas e presas por meio da identificação visual do corante sobre as anteras, a olho nu. Antera solta é definida como aquela exposta, ficando pendente externamente pelo filete. Antera presa é aquela aprisionada entre as extremidades apicais das glumas, sem o filete visível. As anteras soltas têm duração efêmera, ocorrendo a sua deiscência em curto espaço de tempo (24 horas). Por outro lado, as anteras presas permanecem até o final do ciclo da cultura.

Em 1999, no experimento 1, a densidade de espigas foi de $398 \mathrm{~m}^{-2}$. No momento da aplicação dos tratamentos, encontravam-se, em média, 31,7 $\pm 14,5$ anteras soltas por espiga, 4,8 \pm 3,5 anteras presas por espiga e a quantidade total de anteras por espiga foi de $36,5 \pm 15,4$. Durante a aplicação, a temperatura do ar foi de $20{ }^{\circ} \mathrm{C}$, a umidade relativa do ar $60 \%$ e a velocidade do vento $2 \mathrm{~km} \mathrm{~h}^{-1}$, o que não ocasionou deriva em nenhum tratamento. No experimento 2 , a densidade de espigas foi de $390 \mathrm{~m}^{-2}$, encontrando-se, em média, 25,5 $\pm 14,2$ anteras soltas/espiga, 3,3 $\pm 2,4$ anteras presas por 
espiga e a quantidade total de anteras por espiga foi de $28,8 \pm 14,6$. Durante a aplicação, a temperatura do ar foi de $24{ }^{\circ} \mathrm{C}$, a umidade relativa do ar $60 \%$ e a velocidade do vento de $7,2 \mathrm{~km} \mathrm{~h}^{-1}$, ocasionando deriva nos tratamentos em que a solução corante foi aplicada com pontas de jato plano duplo e de jato cônico vazio.

a) Barra Tradicional

b) Barra Modificada

c) Detalhes
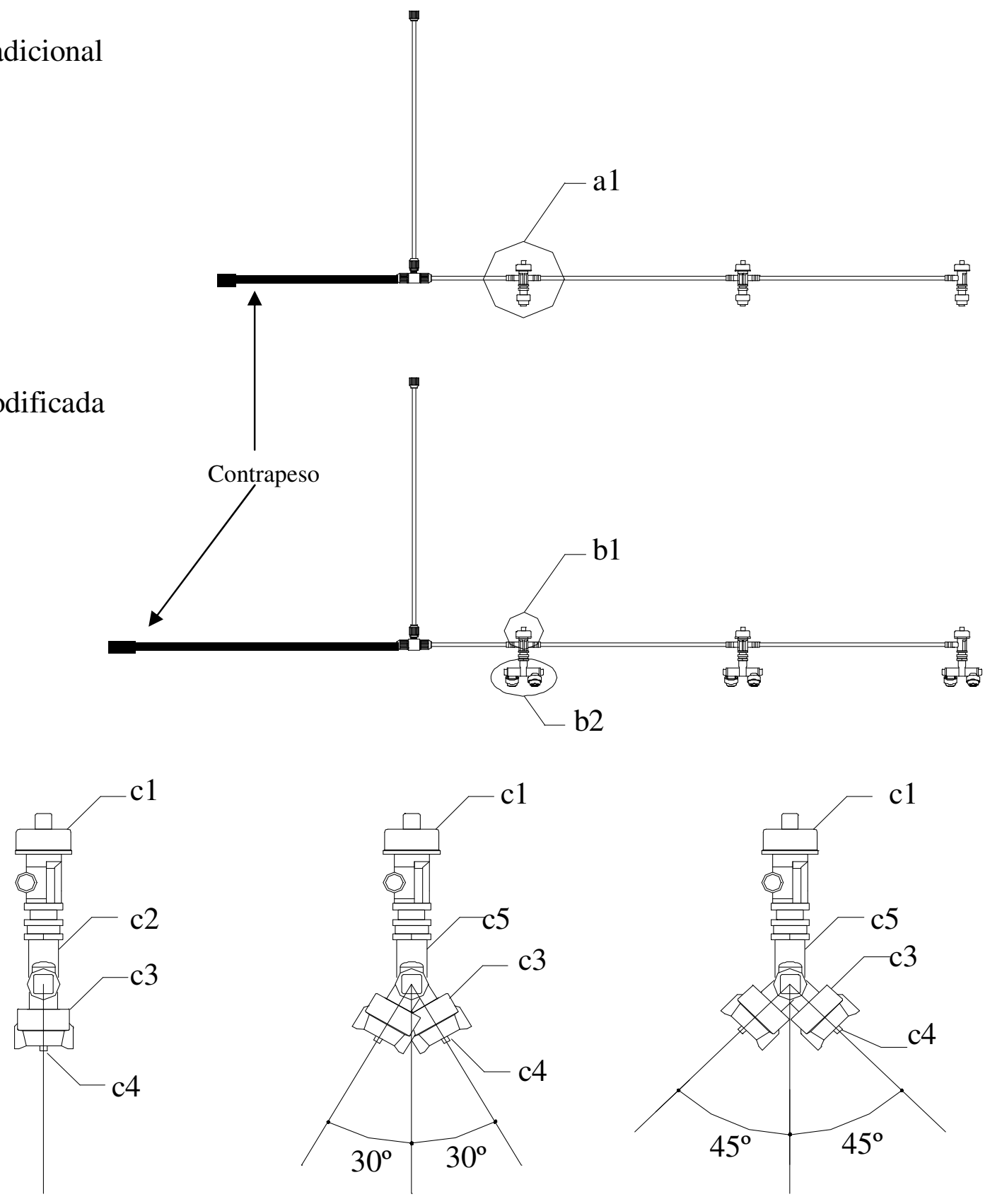

FIGURA 1. Barras utilizadas e detalhes na posição dos bicos. a) barra tradicional - a1) corpo de bico com válvula antigotejante; b) barra modificada - b1) válvula antigotejante, b2) corpo de bico giratório duplo; c) detalhes - c1) válvula antigotejante, c2) corpo de bico, c3) capa, c4) ponta e c5) corpo de bico giratório.

No ano 2000, foram realizados dois experimentos distintos (tratamentos descritos na Tabela 1), cuja aplicação foi realizada no mesmo dia. A densidade de espigas foi de $305 \mathrm{~m}^{-2}$, encontrando-se $28,4 \pm 11,8$ anteras soltas por espiga; $6,9 \pm 3,2$ anteras presas por espiga, totalizando 35,3 $\pm 12,4$ 
anteras por espiga. No momento da aplicação dos tratamentos, a temperatura do ar foi de $27^{\circ} \mathrm{C}$, a umidade relativa do ar $65 \%$ e a velocidade do vento de $1 \mathrm{~km} \mathrm{~h}^{-1}$. A velocidade do vento, a temperatura e a umidade relativa do ar foram determinadas com o auxílio de um termoigroanemômetro portátil (Kestrel 3000).

TABELA 1. Tipo de barra, forma do jato, tipo de ponta, pressão de trabalho e volume de calda utilizados nos experimentos em 1999 e 2000.

\begin{tabular}{|c|c|c|c|c|c|c|}
\hline \multicolumn{7}{|c|}{ Experimentos 1 e $2-1999$} \\
\hline \multirow{2}{*}{ Trat. } & \multirow{2}{*}{ Barra } & \multirow{2}{*}{ Forma do jato } & \multirow{2}{*}{ Ponta } & Pressão & Volume & DMV \\
\hline & & & & $(\mathrm{kPa})$ & $\left(\mathrm{L} \mathrm{ha}^{-1}\right)$ & $(\mu \mathrm{m})$ \\
\hline 1 & Tradicional* & Plano & XR11002 & 200 & 200 & 240 \\
\hline 2 & Tradicional & Plano duplo & $110 \mathrm{DB} 2 * * *$ & 200 & 200 & 155 \\
\hline 3 & Tradicional & Cônico vazio & $\mathrm{JA}-2 * * *$ & 333 & 200 & 90 \\
\hline 4 & Modificada $0^{\circ} * *$ & Plano & XR11002 & 200 & 400 & 240 \\
\hline 5 & Modificada $0^{\circ}$ & Plano duplo & $110 \mathrm{DB} 2$ & 200 & 400 & 155 \\
\hline 6 & Modificada $0^{\circ}$ & Cônico vazio & JA-2 & 333 & 400 & 90 \\
\hline 7 & Modificada $30^{\circ}$ & Plano & XR11002 & 200 & 400 & 240 \\
\hline 8 & Modificada $30^{\circ}$ & Plano duplo & 110DB2 & 200 & 400 & 155 \\
\hline 9 & Modificada $30^{\circ}$ & Cônico vazio & JA-2 & 333 & 400 & 90 \\
\hline \multicolumn{7}{|c|}{ Experimento 3 - 2000} \\
\hline 1 & Tradicional & Plano & XR11002 & 200 & 200 & 240 \\
\hline 2 & Tradicional & Plano duplo & TJ60 11002 & 200 & 200 & 165 \\
\hline 3 & Modificada $30^{\circ}$ & Plano & XR11002 & 200 & 400 & 240 \\
\hline 4 & Modificada $30^{\circ}$ & Plano duplo & TJ60 11002 & 200 & 400 & 165 \\
\hline 5 & Modificada $45^{\circ}$ & Plano & XR11002 & 200 & 400 & 240 \\
\hline 6 & Modificada $45^{\circ}$ & Plano duplo & TJ60 11002 & 200 & 400 & 165 \\
\hline \multicolumn{7}{|c|}{ Experimento 4 - 2000} \\
\hline 1 & Tradicional & Plano & XR11001 & 200 & 100 & 188 \\
\hline 2 & Tradicional & Plano & XR110015 & 200 & 150 & 215 \\
\hline 3 & Tradicional & Plano & XR11002 & 200 & 200 & 240 \\
\hline 4 & Tradicional & Plano duplo & TJ60 11002 & 200 & 200 & 165 \\
\hline 5 & Tradicional & Plano duplo & TJ60 11003 & 200 & 300 & 205 \\
\hline 6 & Tradicional & Plano duplo & TJ60 11004 & 200 & 400 & 240 \\
\hline
\end{tabular}

* Barra tradicional: pontas instaladas em corpos de conexão para um bico, corpos espaçados em 0,50 m, direcionados na vertical.

** Barra modificada: pontas instaladas em corpos de conexão para dois bicos, corpos espaçados em 0,50 m. Dois bicos na vertical $0^{\circ}$; dois bicos, um direcionado $30^{\circ}$ para frente e outro $30^{\circ}$ para trás em relação à vertical; dois bicos, um direcionado $45^{\circ}$ para frente e outro $45^{\circ}$ para trás em relação à vertical (Figura 1).

*** As pontas 110DB2 são da marca Micron e são fabricadas pela Pulsar Tecnologia, Indústria e Comércio Ltda.; as pontas JA-2 são fabricadas pela Indústria Máquinas Agrícolas Jacto S.A., e as demais pontas são de fabricação da Spraying Systems Co.

Obs.: O DMV das gotas foi estimado por meio de gráficos e de tabelas fornecidas pelos fabricantes das pontas.

Nos quatro experimentos, o delineamento experimental foi o inteiramente casualizado. Os dados foram submetidos à análise de variância e comparados por meio do teste de Duncan, a 5\% de probabilidade, quando o teste $\mathrm{F}$ mostrou diferenças significativas, a 5\% de probabilidade.

\section{RESULTADOS E DISCUSSÃO}

A aplicação da solução de corante permitiu estimar a cobertura das anteras, uma vez que, pela diferença de coloração (vermelho vs amarelo), a visualização foi facilitada. Independentemente dos 
tratamentos, a face frontal das espigas aparentou ter recebido mais calda. Isso indica que a cobertura pode não ter sido uniforme em todas as anteras, uma vez que essas se localizam em volta de toda a espiga.

A utilização de dois bicos no mesmo ponto da barra proporcionou o dobro do volume de calda aplicado (200 L ha ${ }^{-1}$ para $400 \mathrm{~L} \mathrm{ha}^{-1}$ ). No experimento 1, os tratamentos 4 a 9, com volume de calda de $400 \mathrm{~L} \mathrm{ha}^{-1}$, apresentaram aumento significativo da porcentagem de anteras cobertas com corante, sejam elas soltas, sejam presas (Tabela 2). Porém, não houve diferenças entre os arranjos dos bicos (tratamentos $4 ; 5 ; 6 ; 7 ; 8$ e 9) ou entre as pontas utilizadas (tratamentos $1 ; 2 ; 3 ; 4 ; 5 ; 6 ; 7 ; 8$ e 9).

TABELA 2. Porcentagem de anteras de trigo (Triticum aestivum) atingidas pela pulverização, utilizando diferentes barras, tipos de pontas, direções dos bicos e volumes de calda. Experimento 1.

\begin{tabular}{|c|c|c|c|}
\hline \multirow{2}{*}{$\begin{array}{c}\text { Tratamentos } \\
\text { Barra - ponta }\end{array}$} & \multirow{2}{*}{$\begin{array}{c}\text { Volume de } \\
\text { Calda }\left(\mathrm{L} \mathrm{ha}^{-1}\right)\end{array}$} & \multicolumn{2}{|c|}{ Anteras com Corante $(\%) *$} \\
\hline & & Soltas & Presas \\
\hline 1 - Tradicional - jato plano & 200 & $51,6 \mathrm{bc}$ & $48,7 \mathrm{bcd}$ \\
\hline 2 - Tradicional - jato plano duplo & 200 & $48,1 \mathrm{c}$ & $46,9 \mathrm{~cd}$ \\
\hline 3 - Tradicional - jato cônico vazio & 200 & $46,9 \mathrm{c}$ & $40,4 \mathrm{~d}$ \\
\hline 4 - Modificada $0^{\circ}$ - jato plano & 400 & $71,0 \mathrm{a}$ & $68,8 \mathrm{a}$ \\
\hline 5 - Modificada $0^{\circ}$ - jato plano duplo & 400 & $68,5 \mathrm{a}$ & $61,7 \mathrm{abc}$ \\
\hline 6 - Modificada $0^{\circ}$ - jato cônico vazio & 400 & $68,3 \mathrm{a}$ & $68,3 \mathrm{a}$ \\
\hline 7 - Modificada $30^{\circ}$ - jato plano & 400 & $67,5 \mathrm{a}$ & $70,0 \mathrm{a}$ \\
\hline 8 - Modificada $30^{\circ}$ - jato plano duplo & 400 & $62,7 \mathrm{ab}$ & $62,8 \mathrm{ab}$ \\
\hline 9 - Modificada $30^{\circ}$ - jato cônico vazio & 400 & $69,3 \mathrm{a}$ & $66,7 \mathrm{a}$ \\
\hline Média & & 61,5 & 59,4 \\
\hline C.V. $(\%)$ & & 13,6 & 16,7 \\
\hline
\end{tabular}

* Médias seguidas da mesma letra na coluna não diferem, significativamente, pelo teste de Duncan, a 5\% de probabilidade.

Da mesma forma que no experimento 1, no experimento 2, a utilização de dois bicos no mesmo ponto da barra (400 $\mathrm{L} \mathrm{ha}^{-1}$ ) resultou em maior número de anteras soltas que receberam corante (Tabela 3). Para as anteras presas, os tratamentos 1 e $3\left(200 \mathrm{~L} \mathrm{ha}^{-1}\right)$ foram semelhantes em todos os tratamentos com $400 \mathrm{~L} \mathrm{ha}^{-1}$.

TABELA 3. Porcentagem de anteras de trigo (Triticum aestivum) atingidas pela pulverização, utilizando diferentes barras, tipos de pontas, direções dos bicos e volumes de calda. Experimento 2.

\begin{tabular}{|c|c|c|c|}
\hline \multirow{2}{*}{$\begin{array}{l}\text { Tratamentos } \\
\text { Barra - ponta }\end{array}$} & \multirow{2}{*}{$\begin{array}{c}\text { Volume de } \\
\text { Calda }\left(\mathrm{L} \mathrm{ha}^{-1}\right)\end{array}$} & \multicolumn{2}{|c|}{ Anteras com Corante $(\%) *$} \\
\hline & & Soltas & Presas \\
\hline 1 - Tradicional - jato plano & 200 & $79,8 \mathrm{bcd}$ & $48,0 \mathrm{ab}$ \\
\hline 2 - Tradicional - jato plano duplo & 200 & $64,8 \mathrm{e}$ & $40,1 \mathrm{~b}$ \\
\hline 3 - Tradicional - jato cônico vazio & 200 & $70,5 \mathrm{de}$ & $49,4 \mathrm{ab}$ \\
\hline 4 - Modificada $0^{\circ}$ - jato plano & 400 & $89,0 \mathrm{ab}$ & 69,6 a \\
\hline 5 - Modificada $0^{\circ}$ - jato plano duplo & 400 & $84,8 \mathrm{ab}$ & $71,2 \mathrm{a}$ \\
\hline 6 - Modificada $0^{\circ}$ - jato cônico vazio & 400 & $83,4 \mathrm{abc}$ & $70,9 \mathrm{a}$ \\
\hline 7 - Modificada $30^{\circ}$ - jato plano & 400 & $92,6 \mathrm{a}$ & $67,0 \mathrm{a}$ \\
\hline 8 - Modificada $30^{\circ}$ - jato plano duplo & 400 & 73,8 cde & $66,0 \mathrm{ab}$ \\
\hline 9 - Modificada $30^{\circ}$ - jato cônico vazio & 400 & $88,8 \mathrm{ab}$ & $74,3 \mathrm{a}$ \\
\hline $\begin{array}{c}\text { Média } \\
\end{array}$ & & 80,8 & 61,8 \\
\hline C.V. (\%) & & 7,9 & 27,1 \\
\hline
\end{tabular}

* Médias seguidas da mesma letra na coluna não diferem, significativamente, pelo teste de Duncan, a 5\% de probabilidade. 
No experimento 2, as pontas de jato plano duplo e jato cônico vazio tenderam a proporcionar menor porcentagem de anteras soltas atingidas pelo corante. O DMV das gotas geradas por essas pontas (respectivamente, 150 e $90 \mu \mathrm{m}$ ), nas condições de velocidade do vento ocorridas no momento da aplicação dos tratamentos $\left(7,2 \mathrm{~km} \mathrm{~h}^{-1}\right)$, favoreceram perdas de calda por deriva. Por outro lado, a utilização das pontas de jato plano (XR-11002) propiciou maior porcentagem de cobertura de anteras com corante. Isso pode ser atribuído ao maior DMV das gotas geradas por essas pontas $(240 \mu \mathrm{m})$ sobre as quais o vento ocorrido acabou tendo um efeito benéfico, deslocando-as da sua trajetória, favorecendo o seu depósito sobre todas as faces das espigas. Essas observações discordam do relato de RAMOS et al. (1998), que estudaram o desempenho de diversos tipos de pontas e observaram que, para atingir as duas faces de alvos verticais (por exemplo, as anteras localizadas em ambas as faces das espigas do trigo), os melhores resultados foram obtidos com pontas de jatos cônicos ou com jatos planos duplos.

No experimento 3, realizado no ano 2000, não foram utilizadas pontas de jato cônico vazio, tendo em vista que, nos dois experimentos conduzidos em 1999, a deposição do corante proporcionada por essas não foi superior às pontas de jatos em leque ou duplos leques e, além disso, não são recomendadas para a utilização em barras (SPRAYING SYSTEMS CO., 1999).

Em relação à presença de corante nas anteras soltas, os tratamentos 5 e 6 apresentaram maior deposição, não diferindo estatisticamente dos tratamentos 2 e 4 (Tabela 4). Enquanto isso, nas anteras presas, não foram observadas diferenças significativas da presença de corante entre os tratamentos. Nesse experimento, verificou-se que os bicos direcionados $45^{\circ}$ para frente e para trás, em relação à vertical, tenderam a apresentar maior porcentagem de anteras atingidas pela calda. Isso indica que os jatos direcionados a $45^{\circ} \mathrm{com}$ a vertical estão atingindo ambas as faces da espiga, o que seria desejável para melhorar o controle da giberela. Em valores absolutos, as pontas de jato plano apresentaram maior cobertura, sugerindo que as gotas mais finas geradas pelas pontas de jato plano duplo são facilmente deslocadas pelo vento e não atingem as anteras, concordando com os relatos de CHRISTOFOLETTI, 1999.

TABELA 4. Porcentagem de anteras de trigo (Triticum aestivum) atingidas pela pulverização, em resposta à utilização de diferentes arranjos dos bicos nas barras, tipos de pontas e volumes de calda. Experimento 3.

\begin{tabular}{|c|c|c|c|}
\hline \multirow{2}{*}{$\begin{array}{c}\text { Tratamentos } \\
\text { Barra - ponta }\end{array}$} & \multirow{2}{*}{$\begin{array}{c}\text { Volume de } \\
\text { Calda }\left(\mathrm{L} \mathrm{ha}^{-1}\right)\end{array}$} & \multicolumn{2}{|c|}{ Anteras com Corante $(\%) *$} \\
\hline & & Solta & Presa \\
\hline 1 - Tradicional - jato plano duplo & 200 & $68,9 \mathrm{~b}$ & 69,4 n.s. \\
\hline 2 - Tradicional - jato plano & 200 & $77,8 \mathrm{ab}$ & 74,4 \\
\hline 3 - Modificada $30^{\circ}$ - jato plano duplo & 400 & $70,6 \mathrm{~b}$ & 79,2 \\
\hline 4 - Modificada $30^{\circ}$ - jato plano & 400 & $77,3 \mathrm{ab}$ & 78,8 \\
\hline 5 - Modificada $45^{\circ}$ - jato plano duplo & 400 & 87,5 a & 75,2 \\
\hline 6 - Modificada $45^{\circ}$ - jato plano & 400 & $90,4 \mathrm{a}$ & 84,3 \\
\hline $\begin{array}{c}\text { Média } \\
\end{array}$ & & 78,8 & 76,9 \\
\hline C.V. $(\%)$ & & 10,7 & 13,0 \\
\hline
\end{tabular}

* Médias seguidas da mesma letra na coluna não diferem, significativamente, pelo teste de Duncan, a 5\% de probabilidade. n.s. - diferenças não significativas pelo teste $\mathrm{F}$, a 5\% de probabilidade.

Pontas com diferentes vazões, que operam na mesma pressão, originam espectros de gotas e volumes de calda diferentes. Pontas de jatos planos e jatos planos duplos com diferentes vazões, que proporcionaram volumes de calda entre 100 e $400 \mathrm{~L} \mathrm{ha}^{-1}$, não apresentaram diferenças significativas de cobertura em anteras soltas (Tabela 5). Já em relação à cobertura das anteras presas, as pontas de jato 
plano duplo proporcionaram maior número de anteras atingidas pelo corante do que as pontas de jato plano (Tabela 5). Nesse caso, o aumento do número de anteras atingidas pela pulverização pode estar relacionado com os maiores volumes de calda e com o maior fracionamento das gotas proporcionado pelas pontas de jato plano duplo, oportunizando que maior número de gotas se depositasse no alvo.

TABELA 5. Porcentagem de anteras de trigo (Triticum aestivum) atingidas pela pulverização, utilizando diferentes pontas de pulverização. Experimento 4.

\begin{tabular}{lccc}
\hline \multirow{2}{*}{ Pontas de Pulverização } & $\begin{array}{c}\text { Volume de } \\
\text { calda }\left(\mathrm{L} \mathrm{ha}^{-1}\right)\end{array}$ & \multicolumn{2}{c}{ Anteras com Corante $(\%) *$} \\
\cline { 3 - 4 } 1 - XR 11001 & 100 & 69,9 n.s. & Presas \\
2 - XR 110015 & 150 & $67,9 \mathrm{~cd}$ \\
3 - XR 11002 & 200 & 68,9 & $57,3 \mathrm{~d}$ \\
4 - TJ60 11002 & 200 & 77,8 & $69,4 \mathrm{bcd}$ \\
5 - TJ60 11003 & 300 & 84,0 & $74,4 \mathrm{abc}$ \\
6 - TJ60 11004 & 400 & 81,5 & $84,3 \mathrm{a}$ \\
\multicolumn{1}{c}{ Média } & & 75,0 & $76,7 \mathrm{ab}$ \\
\hline \multicolumn{1}{c}{ C.V.(\%) } & & 12,5 & 70,8 \\
\hline
\end{tabular}

* Médias seguidas da mesma letra na coluna não diferem, significativamente, pelo teste de Duncan, a 5\% de probabilidade. n.s. - diferenças não significativas pelo teste $\mathrm{F}$, a $5 \%$ de probabilidade.

Em todos os experimentos avaliados, as porcentagens de anteras atingidas pela pulverização com corante variaram de 40 a $93 \%$, indicando que a deposição da calda nas anteras pode ser um fator que limita a eficácia dos fungicidas no campo. Também se pode deduzir que as anteras se constituíram num alvo difícil de ser atingido pelas gotas das pulverizações.

Com relação aos tipos de pontas avaliadas, a quantidade de anteras atingidas pela calda não diferiu entre as formas dos jatos gerados, exceto quando se utilizaram de pontas de jato plano duplo, com aplicação de volume de calda de 300 e $400 \mathrm{~L} \mathrm{ha}^{-1}$. Na maioria dos casos avaliados, a ponta de jato plano (leque XR-11002), montada na barra tradicional, comportou-se de maneira semelhante aos melhores tratamentos, podendo ser recomendada para a aplicação de fungicida, visando ao controle da giberela.

Mc MULLEN (1998) relata que as aristas podem interferir na deposição da calda sobre as anteras. Em todas as situações, um fator que pode ter influenciado na deposição das gotas foram as aristas. Elas foram coloridas, indicando que as gotas, ao encontrá-las, depositam-se ou então se fragmentam, formando gotas muito finas, cuja quantidade de ingrediente ativo seria tão pequena que possivelmente não teria efeito fungicida. Neste sentido, seria importante verificar a cobertura das anteras em trigos múticos (sem aristas) para confirmar se as aristas interferem na deposição da calda.

Em todos os experimentos, as anteras presas apresentaram menor percentagem de deposição do corante. Em vista disso, pode-se deduzir que as anteras presas são dificilmente atingidas, uma vez que são relativamente "pequenas" e ficam presas entre as glumas apenas com o ápice exposto. Segundo REIS et al. (1996), as anteras presas são epidemiologicamente as mais importantes e necessitam de serem protegidas com o fungicida para prevenir epidemias. Ainda persiste o desafio de depositar o fungicida nestes sítios de infecção tão pequenos e protegidos. Portanto, é necessário estudar outras técnicas de controle ou ingredientes ativos que sejam mais eficazes e capazes de paralisar o processo pós-infecção.

Outro ponto que deve ser considerado, é a desuniformidade da antese em trigo (REIS, 1988; VARGAS et al., 2000). Se parte das anteras expostas não recebem a calda, pode-se concluir que a possibilidade de atingir todas as anteras é muito remota, e, então, o controle químico é dificultado, 
tornando-se pouco promissor. Por outro lado, se o controle obtido com os fungicidas, mesmo que moderado (60\% de controle), é economicamente viável, deve-se utilizá-lo, principalmente nas regiões onde os riscos de danos causados pela doença são maiores.

\section{CONCLUSÕES}

Tomando os resultados no seu conjunto, pode-se concluir que a modificação da barra, com bicos montados em corpos duplos giratórios, formando ângulos de $45^{\circ} \mathrm{com}$ a vertical, bem como o aumento do volume de calda de $200 \mathrm{~L} \mathrm{ha}^{-1}$ para $400 \mathrm{~L} \mathrm{ha}^{-1}$ são medidas efetivas para aumentar o grau de cobertura do alvo biológico em estudo.

Da mesma forma, na comparação entre as pontas, a utilização de pontas com jatos planos duplos, quando comparada com pontas de jatos planos, que geram gotas de tamanho similar, mostra uma tendência a atingirem um maior número de anteras.

\section{REFERÊNCIAS BIBLIOGRÁFICAS}

CHRISTOFOLETTI, J.C. Boletim técnico BT-05/99 - Considerações sobre tecnologia de aplicação de defensivos agrícolas. Disponível em: <http://www.teejet.com.br>. Acesso em: 01 jul. 1999.

MAROCHI, A.I. Conquiste o futuro com a tecnologia presente: tecnologia de aplicação de defensivos. Castro: Fundação ABC, 1996. 24 p.

MATTHEWS, G.A. Pesticide application methods. 2.ed. London: Longman, 1992. 334 p.

MATUO, T. Técnicas de aplicação de defensivos agrícolas. Jaboticabal: FUNEP, 1990. 139 p.

MAULER-MACHNIK, A.; ZAHN, K. Ear fusarioses in wheat - new findings on their epidemiology and control with Folicur (tebuconazole). Pflanzenschutz Nachrichten Bayer, Leverkusen, v.47, p.129$55,1994$.

Mc MULLEN, M. Fungicide technology network of the national FHB initiative - 1988. In: NATIONAL FUSARIUM HEAD BLIGHT FORUM, 1998, East Lansing. Proceedings... Michigan: Michigan State University, 1998. p.47-50.

OZEKI, Y.; KUNZ, R.P. Tecnologia de aplicação aérea: aspectos práticos. In: GUEDES, J.V.C.; DORNELLES, S.H.B. Tecnologia e segurança na aplicação de agrotóxicos: novas tecnologias, 1998, Santa Maria. Anais... Santa Maria: Universidade Federal de Santa Maria / Sociedade de Agronomia de Santa Maria, 1998. p.65-78.

PARRY, D.W.; JENKINSON, P.; Mc LEOD, L. Fusarium ear blight (scab) in small grain cereals - a review. Plant Pathology, London, v.44, p.207-38, 1995.

RAMOS, H.H.; MATUO, T.; ALMEIDA, A.N.; PIO, L.C. Cobertura do alvo pela pulverização com bico hidráulico em função do tipo de jato, posição do alvo e altura de aplicação. In: CONGRESSO BRASILEIRO DE ENGENHARIA AGRÍCOLA, 27., 1998, Poços de Caldas. Anais... Poços de Caldas: Sociedade Brasileira de Engenharia Agrícola, 1998. p.169.

REIS, E.M. Doenças do trigo III: giberela. 2.ed. São Paulo: E.M. REIS, 1988. 13 p.

REIS, E.M.; FERNANDES, J.M.; PICININI, E.C. Estratégias para o controle de doenças do trigo. Passo Fundo: Embrapa-CNPT, 1988. 50 p.

REIS, E.M.; BLUM, M.M.C.; CASA, R.T. Controle químico de Gibberella zeae em trigo - um problema de deposição de fungicidas em anteras. Summa Phytopathologica, São Paulo, v.22, p.39-42, 1996. 
REIS, E.M.; CASA, R.T; FORCELINI, C.A. Doenças do trigo. In: KIMATI, H.; AMORIM, L.; BERGAMIN FILHO, A.; CAMARGO, L.E.A.; REZENDE, J.A.M. Manual de Fitopatologia: doenças de plantas cultivadas. 3.ed. São Paulo: Agronômica Ceres, 1997. p.725-36.

SAYLER, T. NDSU research yields more clues for improving fungicide application techniques. Disponível em: <http://www.smallgrains.org>. Acesso em: 14 jul. 1997.

SPRAYING SYSTEMS. Catálogo 46M-BR/P: produtos de pulverização para a agricultura. Diadema, 1999. $104 \mathrm{p}$.

TEIXEIRA, M.M.; DELGADO, L.M.; FIGUEIREDO, J.L.A. Efeito do volume de pulverização e da população de gotas na eficácia de tratamentos herbicidas, utilizando pulverizadores hidráulicos. In: CONGRESSO BRASILEIRO DE ENGENHARIA AGRÍCOLA, 27., 1998, Poços de Caldas. Anais... Poços de Caldas: Sociedade Brasileira de Engenharia Agrícola, 1998. p.115.

VARGAS, P.R.; FERNANDES, J.M.; PICININI, E.C.; HUNT, A.L. Simulação de epidemia de giberela em trigo. Fitopatologia Brasileira, Brasília, v.25, p.497-504, 2000.

VELLOSO, J.A.R. de O.; GASSEN, D.N.; JACOBSEN, L.A. Tecnologia de aplicação de defensivos agrícolas com pulverizadores de barra. Passo Fundo: Embrapa-CNPT, 1984. 52 p.

ZADOCKS, J.C.; CHANG, T.T.; KONZAC, C.F. A decimal code for the growth stages of cereals. Weed Research, Oxford, v.14, p.415-21, 1974. 